\title{
The Association Between Physical Violence Experience and Post-Traumatic Stress Disorder in Emergency Department Nurses: The Moderating Role of Isolation
}

\author{
Sung Hee Lee ${ }^{1}$ and Min Kyong Kim ${ }^{2}$ \\ Graduate School of Nursing, Kyungpook National University, Daegu, S. Korea \\ faith0618@knu.ac.kr
}

\begin{abstract}
The present study aimed to investigate the moderating role of isolation in the relationship between physical violence experience and post-traumatic stress disorder in emergency department nurses. Physical violence experience, post-traumatic stress disorder, and isolation of self-compassion were measured using a structured questionnaire among 96 nurses in the emergency departments located in D and $G$ cities in South Korea from June to July of 2017. The collected data were analyzed using IBM SPSS Statistics 20.0 and SPSS PROCESS Macro. The results showed that isolation was significantly and positively correlated with post-traumatic stress disorder. The explanatory power for post-traumatic stress disorder in emergency department nurses increased when the interaction between isolation and physical violence experience was entered. The high-isolation group showed higher increase in post-traumatic stress disorder than the low-isolation group. Isolation was found to be the moderator that increased the negative influence of physical violence experience on post-traumatic stress disorder. The findings suggest that consideration should be given to the fact that the effect of physical violence experience on post-traumatic stress disorder varies depending on the level of isolation of emergency department nurses when developing intervention programs for post-traumatic stress disorder in emergency department nurses.
\end{abstract}

Keywords: Emergency department nurse, Physical violence experience, Post-traumatic stress disorder, Self-compassion, Isolation

\section{Introduction}

\subsection{The need for research}

The physical violence experience rate among domestic emergency department nurses is $46 \%$ while a rate of $52 \%$ has been reported abroad [1]. This is twice the physical violence experience rate of nurses working in intensive care units or postanesthetic recovery units [2].

Emergency department nurses not only are injured by physical violence but also seriously suffer from emotional aftereffects such as depression, anxiety, or fear [3]. The negative emotion due to physical violence experience and fear of contact with patients among emergency department nurses leads to avoidance effort in response to trauma-related signals, which causes post-traumatic stress disorder [4][5]. Post-traumatic stress disorder reduces the

Article history:

Received (October 2, 2017), Review Result (November 10, 2017), Accepted (December 22, 2017) 
quality of life of emergency department nurses in personal health and life in general [6]. Decrease in thinking and concentration of emergency department nurses experiencing posttraumatic stress disorder and reduction in communication and emotional support for patients negatively influence patient nursing [7].

Post-traumatic stress disorder, however, does not occur in all emergency department nurses who have experienced physical violence [8]. The expression of post-traumatic stress disorder depends on personal internal resources that can offset the effect of traumatic events and effective coping methods using one's ability. Individuals can recover from the experience of shocking traumatic events, and this ability works as a factor that can control rumination and post-traumatic stress disorder [9][10].

Isolation is one of the attributes of self-compassion and an egocentric way of thinking of adversity. It indicates the characteristic of thinking and behaving from one's own perspective, need, and position by perceiving the outside centered on oneself. Recently, self-compassion is drawing attention as a protective psychological variable in mental health research [11][12][13][14]. Isolation causes self-centered uniform thinking due to the absence of ability to turn attention to other aspects [11]. As a result, isolation works as a predictor of rumination and burnout and is positively related to the avoidance symptom of post-traumatic stress disorder [15].

While many studies have reported that the physical violence experience of emergency department nurses and medical technicians affects post-traumatic stress disorder, no research has investigated the moderating effect of isolation. Accordingly, the present study intended to determine the applicability and moderating effect of isolation in the relationship between physical violence experience and post-traumatic stress disorder in emergency department nurses. In addition, the results will be provided as basic data for the development of intervention programs for post-traumatic stress disorder of emergency department nurses who are experiencing physical violence.

\section{Research method}

\subsection{Research design}

The present study used a descriptive survey to determine the relationships among physical violence experience, post-traumatic stress disorder, and isolation in emergency department nurses and the moderating effect of isolation.

\subsection{Participants and data collection}

Participants were 96 emergency department nurses working at seven different secondary and tertiary care hospitals located in D and G cities. The selection criteria were having been working at least one year in the emergency department, understanding the purpose of the present study, and agreeing to participate. Questionnaires were distributed after obtaining cooperation from seven hospitals from June to July of 2017, and 107 responses were collected. Among the collected questionnaires, 96 were used in the analysis with 11 responses excluded due to insincerity.

\subsection{Research instruments}

Physical violence experience. To measure physical violence experience, the physical violence type and frequency portion of the violence experience scale developed by Yun Jong- 
suk [16] were used after modification and supplementation. It is composed of eight items that measure the frequency of experience depending on the types of physical violence.

Post-traumatic stress disorder. The PTSD Checklist for DSM-5 developed by Weathers et al. [17] and translated into Korean by Sim So-yeon [18] was used. The instrument is composed of a total of 20 items of re-experience, avoidance, negative changes in cognition and mood, and hyperarousal.

Isolation. Isolation was measured using four items of isolation among 26 items in six subfactors of self-kindness, universal humanity, mindfulness, self-judgment, isolation, and overidentification of the Self-Compassion Scale developed by Neff [12] and translated into Korean by Kim Gyeong-ui et al. [19].

\subsection{Ethical considerations}

The data collection for the present study was conducted after approval was received from the IRB of the institution the investigators are affiliated (IRB 2017-0050).

\subsection{Data analysis}

The collected data were analyzed using IBM SPSS Statistics 20.0 and SPSS PROCESS Macro.

\section{Results}

3.1. Averages and standard deviations of physical violence experience, isolation, and post-traumatic stress disorder and correlations among them

Participants' average scores of physical violence experience, isolation, and post-traumatic stress disorder were $5.27( \pm 7.24), 8.50( \pm 3.27)$, and $25.85( \pm 17.06)$, respectively.

Physical violence experience showed nonsignificant correlations with isolation and posttraumatic stress disorder, but isolation showed significant positive correlation with posttraumatic stress disorder (Spearman's Rho $=397, \mathrm{p}<.001$ ).

Table 1. Means, standard deviations, and correlations for the study variables $(\mathrm{N}=96)$

\begin{tabular}{|c|c|c|c|}
\hline \multirow{2}{*}{ Variables } & $\begin{array}{c}\text { Physical Violence } \\
\text { Experience }\end{array}$ & Isolation & PTSD \\
\cline { 2 - 4 } & \multicolumn{2}{|c|}{$\mathrm{r}(\mathrm{p})$} \\
\hline $\begin{array}{c}\text { Physical Violence } \\
\text { Experience }\end{array}$ & 1 & - & - \\
\hline Isolation & .076 & 1 & - \\
\hline PTSD & $(.461)$ & $\begin{array}{c}.397 \\
(<.001)\end{array}$ & 1 \\
\hline $\mathrm{M}$ & $\begin{array}{c}.187 \\
(.068)\end{array}$ & 8.50 & 25.85 \\
\hline SD & 5.27 & 3.27 & 17.06 \\
\hline
\end{tabular}




\subsection{The moderating effect of isolation}

Physical violence experience was found to significantly influence post-traumatic stress disorder by interacting with isolation. That is, the explanatory power of post-traumatic stress disorder was $24.9 \%$, which was a $5 \%$ increased, as a result of entering the interaction between physical violence experience and isolation $(\mathrm{F}=10.185, \mathrm{p}<.001)$.

Table 2. Moderating effect of isolation $(\mathrm{N}=96)$

\begin{tabular}{|c|c|c|c|c|c|c|c|c|}
\hline & Variables & $\mathrm{B}$ & $\beta$ & $\mathrm{t}$ & $p$ & $\mathrm{R}^{2}$ & Adj. $^{2}$ & $\mathrm{~F}(p)$ \\
\hline \multirow{2}{*}{1} & 25.849 & & 16.413 & $<.001$ & .199 & .182 & 11.578 \\
\cline { 2 - 9 }$($ Constant) & $\begin{array}{c}\text { Physical Violence } \\
\text { Experience }\end{array}$ & .426 & .181 & 1.945 & $<.001$ & - & - & $(<.001)$ \\
\cline { 2 - 9 } 2 & 2.175 & .416 & 4.483 & $<.001$ & & & \\
\hline Isolation & $\begin{array}{c}\text { Physical Violence } \\
\text { Experience }\end{array}$ & .642 & .272 & 2.786 & .005 & - & - & $(<.001)$ \\
\cline { 2 - 9 } & \begin{tabular}{c} 
Isolation \\
\cline { 2 - 9 }
\end{tabular} & 2.056 & .394 & 4.332 & $<.001$ & - & - & - \\
\cline { 2 - 9 } & $\begin{array}{c}\text { Physical Violence } \\
\text { Experience }\end{array}$ & .168 & .243 & 2.474 & .015 & - & - & - \\
\hline
\end{tabular}

\subsection{Significance test of simple regression line according to conditional effect of isolation}

To determine the value of the mediating variable measured as a continuous variable in which moderating effect was found, the simple regression line, which was the effect of physical violence experience on post-traumatic stress disorder, was tested when the moderating variable took a specific value (mean value and mean $\pm 1 \mathrm{SD}$ ). The results showed that the effect of physical violence experience on post-traumatic stress disorder at specific values of isolation were all statistically significant. In the case of "low" isolation, the score of post-traumatic stress disorder significantly increased from 23.75 to 29.93 when the level of physical violence experience increased but the change was small $(\mathrm{t}=2.55, \mathrm{p}=.012)$; in the case of "high" isolation, however, the change was large $(t=3.127, p=.002)$ with the score of post-traumatic stress disorder significantly increased from 32.14 to 47.54 . That is, the "high" isolation group showed larger increase of post-traumatic stress disorder than the "low" isolation group.

Table 3. Simple slope test of isolation according to conditional effect $(\mathrm{N}=96)$

\begin{tabular}{|c|c|c|c|c|c|c|}
\hline Isolation & $\mathrm{b}$ & $\mathrm{SE}$ & $\mathrm{t}$ & $\mathrm{p}$ & LLCI & ULCI \\
\hline$-1 \mathrm{SD}$ & .561 & .220 & 2.550 & .012 & .124 & .998 \\
\hline $\mathrm{M}$ & 1.065 & .335 & 3.180 & .002 & .400 & 1.730 \\
\hline$+1 \mathrm{SD}$ & 1.400 & .448 & 3.127 & .002 & .511 & 2.290 \\
\hline
\end{tabular}




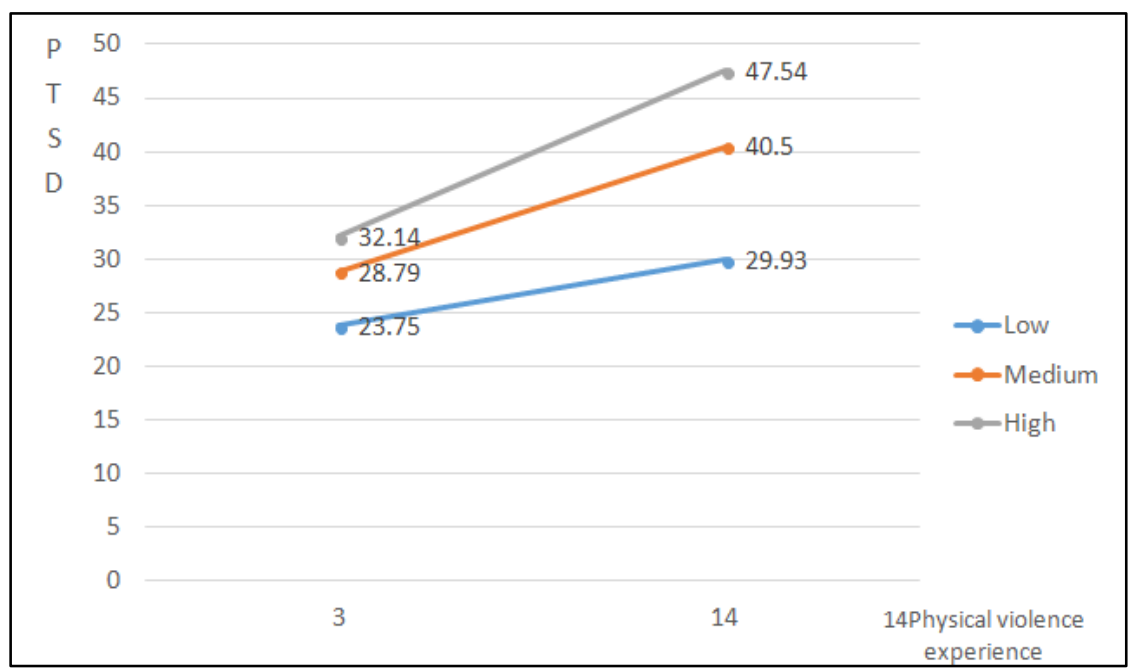

Figure 1. Interaction of physical violence experience with isolation on PTSD

\section{Discussion}

The present study investigated the moderating effect of isolation in the relationship between physical violence experience and post-traumatic stress disorder in 96 emergency department nurses. The results showed that the effect of physical violence experience on posttraumatic stress disorder varied depending on the level of isolation. Isolation was found to be the moderator that increased the negative influence of physical violence experience on posttraumatic stress disorder.

The high-isolation group showed higher increase in post-traumatic stress disorder than the low-isolation group. The effect of isolation was confirmed in that post-traumatic stress disorder in emergency department nurses due to physical violence experience increased when the level of isolation was high. Therefore, the significance of the present study lies in providing understanding of the necessity to consider that the physical violence experience of emergency department nurses is not unconditionally expressed as post-traumatic disorder but, rather, varies depending on the level of isolation of emergency department nurses.

\section{Conclusion}

The results of the present study confirmed the moderating role of isolation in the relationship between physical violence experience and post-traumatic stress disorder. The results of the present study suggest that consideration should be given to the fact that the effect of physical violence experience on post-traumatic stress disorder varies depending on the level of isolation of emergency department nurses when developing intervention programs for post-traumatic stress disorder in emergency department nurses.

\section{Reference}

[1] B. Partridge and J. Affleck, "Verbal abuse and physical assault in the emergency department: Rates of violence, perceptions of safety, and attitudes towards security," Australasian Emergency Nursing Journal, vol.20, no.3, pp.139-145, (2017)

[2] J.M. Laposa and L. E. Alde and L. M. Fullerton, "Work stress and posttraumatic stress disorder in ED nurses/personnel”, Journal of Emergency Nursing, vol.29, no.1, pp.23-28, (2003) 
[3] J. Zeng, F. An, Y. Xiang, Y. Qi, G.S. Ungvari, R. Newhouse, Y. Ding, W.K. Tang, P.P. Wu, Z.J. Hou, and H.F. Chiu "Frequency and risk factors of workplace violence on psychiatric nurses and its impact on their quality of life in China," Psychiatry Research, vol.210, no. 2, pp.510-514, (2013)

[4] B. Mroczek, J. Mormul, A. Kotwas, M. Szkup, and D. Kurpas, "Patient aggression towards health care professionals," Progress in Health Sciences, vol.4, no.2, (2014)

[5] J.M. Laposa, L.E. Alden, and L.M. Fullerton, "Work stress and posttraumatic stress disorder in ED nurses/personnel,” Journal of Emergency Nursing, vol.29, no.1, pp.23-28, (2003)

[6] C. Lauvrud, K. Nonstad, and T. Palmstierna, "Occurrence of post traumatic stress symptoms and their relationship to professional quality of life (ProQoL) in nursing staff at a forensic psychiatric security unit: A cross-sectional study," Health and Quality of Life Outcomes, vol.7, no.1, (2009)

[7] D. M. Gates, G. L. Gillespie, and P. Succop, "Violence against nurses and its impact on stress and productivity," Nursing Economics, vol.29, no.2, pp.59-66, (2011)

[8] G. L. Gillespie, S. Bresler, D. M. Gates, and P. Succop, "Posttraumatic stress symptomatology among emergency department workers following workplace aggression," Workplace Health \& Safety, vol.61, no.6, pp.247-254, (2013)

[9] L. Hyuk and P. Oe Byeong, Korean Police Research, vol.14, no.3, (2015)

[10] J. Lee, H. Choi, J. Kim, J. Nam, H. Kang, S. Koh, and S. Oh, "Self-resilience as a protective factor against development of post-traumatic stress disorder symptoms in police officers," Annals of Occupational and Environmental Medicine, vol.28, no.1, (2016) DOI: 10.1186/s40557-016-0145-9

[11] K.D. Neff, "Self-Compassion: An alternative conceptualization of a healthy attitude toward oneself," Self and Identity, vol.2, no.2, (2003) DOI: 10.1080/15298860309032

[12] K.D. Neff, "The development and validation of a scale to measure self-compassion," Self and Identity, vol.2, no.3, (2003) DOI: 10.1080/15298860309027

[13] K.D. Neff, "Self-compassion and psychological well-being," Constructivism in the Human Sciences, vol.9, no.2, pp.27-38, (2004)

[14] K.D. Neff, Y. Hsieh, and K. Dejitterat, "Self-compassion, achievement goals, and coping with academic failure," Self and Identity, vol.4, no.3, (2005)

[15] B.L. Thompson and J. Waltz, "Self-compassion and PTSD symptom severity," Journal of Traumatic Stress, vol.21, no.6, pp.556-558, (2008) DOI: 10.1002/jts.20374

[16] Y. Jong Sook, "A study on violence and job satisfaction by patients and caregivers experienced by emergency center nurses," M.S. Thesis, Ulsan University, (2004)

[17] C.A. Blevins, F.W. Weathers, M.T. Davis, T.K. Witte, and J.L. Domino, "The posttraumatic stress disorder checklist for dsm-5 (pcl-5): development and initial psychometric evaluation,” Journal of Traumatic Stress, vol.28, no.6, pp.489-498, (2015) DOI: 10.1002/jts.22059

[18] S. So Yeon, "Depression, D type personality, and posttraumatic stress disorder in adult and elderly subjects with acute coronary syndrome," M.S. thesis, Ewha Woman's University, (2014)

[19] K. Kyung Ui, I. Geum Dan, J. Yong Rae, Ch. Sook Hee, and I. U Kyung, Korean Psychological Association: Health, vol.13, no.4, (2008) 